Deferred Compensation and Gift Exchange:

An Experimental Investigation into Multi-Period Labor Markets

Steffen Huck, University College London, ELSE, IZA

Andrew J. Seltzer, Royal Holloway College

Brian Wallace, Royal Holloway College

We gratefully acknowledge a grant from the Nuffield Foundation. In addition, the first author acknowledges financial support from the Economic and Social Research Council (UK) via the Centre for Economic Learning and Social Evolution (ELSE). 


\title{
Deferred Compensation and Gift Exchange: An Experimental Investigation into Multi-Period Labor Markets
}

\begin{abstract}
This paper examines the relationship between firms' wage offers and workers' supply of effort using a three-period experiment. In equilibrium, firms will offer deferred compensation: first period productivity is positive and wages are zero, while third period productivity is zero and wages are positive. The experiment produces strong evidence that deferred compensation increases worker effort; in about 70 percent of cases subjects supplied the optimal effort given the wage offer, and there was a strong effort response to future-period wages. We also find some evidence of gift exchange; worker players increased the effort levels in response to above equilibrium wage offers by a human, but not in response to similar offers by a computer. Finally, we find that firm players who are initially hesitant to defer compensation learn over time that it is beneficial to do so.
\end{abstract}


Few questions in labour economics have been the subject of as much attention as the effect of workplace incentives on worker effort. It has been argued that firms will tend to offer 'hard' incentive-based schemes such as piece rates or commissions if workers' performance can be easily monitored. Recent empirical studies have shown that workplace incentive schemes produce significant effort responses from employees. (Lazear (2000) and Prendergast (1999)). However, it is also recognized that if jobs involve multi-tasking or output is difficult to measure, workers may respond perversely to simple incentive schemes. For example, workers may increase the quantity of output while reducing quality. Alternatively, workers may devote an inefficiently high amount of time to tasks that are easily measured and inefficiently low amount of time at tasks that are more difficult to measure. For this reason, the argument goes, many firms do not use simple performance-based pay schemes, and instead attempt to reward long-term performance rather than short-term output.

One incentive scheme that ties rewards to longer-run measures of performance is deferred compensation. (Lazear (1979)). In a deferred compensation contract the worker/employer relationship is expected to be long-term. Workers are underpaid during the early part of their career (that is pay $<$ marginal revenue product) and overpaid during the later part of their career. This structure of compensation encourages higher effort; future pay always exceeds future productivity, thus workers have an incentive not to undertake actions that will lead to dismissal. ${ }^{1}$ There are two ancillary incentive problems with deferred compensation contracts. First, firms have an incentive to renege on the contract and dismiss older workers whose pay exceeds productivity. This problem can be avoided by legally binding long-term contracts or by reputation mechanisms (i.e. a firm that dismisses older workers may have difficulty recruiting young workers in the future). Second, because older workers are overpaid, they will have an incentive to remain on the job past the optimal retirement point. This problem can be solved by a policy of mandatory retirement.

Because deferred compensation is an optimal contract only when there exist difficulties measuring short-term effort and output, there is an inherent problem in testing the theory directly. If the researcher were able to measure the effect of deferred compensation on performance then the employer should be able to use other schemes. So, unsurprisingly, we are not aware of any empirical studies on the impact of deferred compensation on worker behavior. Instead the existing literature focuses on whether mandatory retirement and steep age earnings profiles are associated with jobs with monitoring difficulties (Hutchens (1987)); whether mergers or high bankruptcy probabilities are associates with flatter wage profiles (Gokhale et. al (1995)); and whether wages increase too much in later years of the career to be explained by productivity increases (Seltzer and Merrett (2000)).

This paper directly examines the relationship between deferred compensation and worker effort levels using experimental evidence. We create a simple three-period model with equilibrium predictions of deferred compensation and positive worker effort. The

${ }^{1}$ Deferred compensation contracts have also been shown to reduce quits and attract future-minded employees. Salop and Salop (1976). We do not analyze these properties in this paper. 
model captures several of the important features of the Lazear model: namely equilibrium underpayment of young workers, equilibrium overpayment of retired workers, equilibrium worker effort higher than in a spot labor market, and mandatory retirement. The basic structure of the experiment is as follows. In the first stage the firm player makes a binding wage offer for the 3 stages. The worker player then decides the level of effort to supply. If they supply low effort, the round ends with some probability; if they supply medium or high effort, the round continues to the second stage. The worker faces the same decision again in the second stage. The third stage corresponds to retirement, and, if it is reached, the firm player gives the worker player the pension promised at the start of the first stage. The experiment is designed such that higher effort increases productivity but has costs for the worker player. We ran the experiments with random matching of worker and firm players over 20 rounds in order to provide opportunities for learning while essentially keeping the strategic incentives of a one-shot game.

Another issue that we examine in this paper is the importance of fairness and giftgiving to the supply of effort. There exists a large literature in economics, sociology, and management that argues that gift-exchange may be as important as incentives to the supply of effort. Akerlof (1982) argues that labor contracts often contain partial gift exchanges whereby employers give workers above-market wages and workers give employment effort greater than what is necessary to avoid dismissal. Akerlof and Yellen (1990) argue that workers may withhold effort if they perceive their wages to be unfairly low. They further argue that in some cases workers will lower their own earnings in order to punish their employer for unfair wages.

There is also considerable experimental evidence that considerations of fairness and reciprocity induce subjects to deviate from equilibrium predictions. For example, Fehr, Kirchsteiger, and Riedl $(1993,1996)$ provide strong evidence for positive reciprocity and gift exchange. In these experiments workers respond to higher wages with choosing higher efforts even when they would maximize their income by choosing low efforts regardless of the wage. This form of gift exchange makes both, firm and worker, better off than they would be in equilibrium. ${ }^{2}$ Falk and Gachter (2002) show that this effect of reciprocity is reinforced in repeated-game settings further increasing efficiency. The presence of reciprocity, fairness and gift exchange also affects the optimal design of contracts. Fehr, Klein, and Schmidt (2001) show, for example, that contracts that would be optimal if all agents were selfish can be rather bad for the firm if some workers are fair-minded. They also provide experimental evidence for this claim. ${ }^{3}$

As earlier studies, our experiment incorporates fairness considerations by allowing firm players to provide above-optimal compensation and worker players to supply aboveoptimal effort at each decision point. Depending on the wage offer, the worker player may also be able to supply below-optimal effort. We test for the importance of fairness to

\footnotetext{
${ }^{2}$ However, in a competitive labour market gift exchange causes involuntary unemployment which makes some players (the unemployed) actually worse off. See also Fehr and Falk (1999) who show that firms do not accept offers from unemployed workers to work for less since they rightly fear that this destroys the benefits of reciprocal gift exchange. This gives rise to wage rigidities.

${ }^{3}$ Along similar lines, Bohnet, Frey, and Huck (2001) as well as Fehr and Gachter (2002) show how pecuniary incentives can crowd out intrinsic motivations and, thus, worsen performance.
} 
worker behavior using two strategies. First, we look for evidence of gift exchange by examining whether above-optimal effort is a response to above-optimal wage offers. Second, we run a treatment where the role of the firm is played by a computer. We assume that subjects do not wish to give gifts to the computer, thus if worker players' behavior is the same in the two treatments we conclude that actions off the equilibrium path are due to genuine mistakes rather than gift giving.

The remainder of the paper is organized as follows. The first section outlines a simple three-period model of a deferred compensation contract which captures the essential features of Lazear's deferred compensation model. The second section describes the design of our experiment. The third section presents the results from both treatments. The fourth section concludes. It is shown that subjects behave largely in accordance with the predictions of the Lazear model. When offered deferred compensation, subjects supplied considerably higher levels of effort than when compensation was front loaded. This is learned by firm players who pay ever increasing shares of the total wage in the last period. We also find some evidence for gift exchange. Worker players increased their effort levels in response to some wage offers with no theoretical incentive effects during the treatment with human firm players, but not to the same offers during the treatment with a computer firm player. However, the magnitude of effort increases in response to wage offers off the equilibrium path is far smaller than incentive-induced effort increases.

\section{The Model}

Figure 1 shows a deferred compensation contract. In a competitive labor market, the contract offers lifetime wages that are equal in net present value to lifetime productivity; however, wages are less than productivity prior to $\mathrm{T}^{*}$ and greater than productivity thereafter. ${ }^{4}$ These contracts normally contain two additional features to provide optimal incentives: mandatory retirement and policies that make it difficult for firms to dismiss older workers. In order for lifetime wages to be no greater than lifetime productivity, the worker must retire at or before $\mathrm{T}^{* *}$. At the start of the contract the worker is indifferent to the wage payments shown with retirement at $\mathrm{T}^{* *}$ and a contract with wage equal to MRP. However, under the deferred compensation contract she will continue working past $\mathrm{T}^{* *}$, unless the contract contains a mandatory retirement provision. It is necessary to have provisions that make dismissal of older workers difficult in order to prevent firms from reneging on the implicit contract and dismissing the worker at $\mathrm{T}^{*}$. Firms can commit not to renege through legally binding contracts such as "last hired, first fired" or through informal mechanism that depend on maintaining an honest reputation in order to recruit workers in the future.

\footnotetext{
${ }^{4}$ The competitive labor market assumption is not necessary to capture the main points of Lazear model. Our model does not assume competitive labor markets, and in equilibrium lifetime wages are less than lifetime productivity. One consequence of assuming a non-competitive labor market is that our experiments do not have an obvious focal point whereby the subjects split the earnings for the round.
} 
Our experiments use a discretized version of Lazear's continuous time model with three periods reflecting the phases before $\mathrm{T}^{*}$, between $\mathrm{T}^{*}$ and $\mathrm{T}^{* *}$, and after $\mathrm{T}^{* *}$ (henceforth referred to as young worker - stage 1 , old worker - stage 2 , and retired worker - stage 3 ). At the start of each round firm players have to decide about wages for the first two periods and about a pension for the third

$$
\left(\mathrm{W}_{1}, \mathrm{~W}_{2}, \mathrm{~W}_{3}\right) \in \boldsymbol{R}_{+0}^{3} \text {. }
$$

Worker players have to decide their effort level in periods 1 and 2, which is modeled as a triple decision (low, medium, high). High effort leads to output $\mathrm{Z}_{\mathrm{H}}$ which is assumed to be greater than the output under medium effort, $Z_{\mathrm{M}}$, and, likewise, output under medium effort is greater than output under low effort $\mathrm{Z}_{\mathrm{L}}$, such that

$$
\mathrm{Z}_{\mathrm{H}}>\mathrm{Z}_{\mathrm{M}}>\mathrm{Z}_{\mathrm{L}}
$$

We assume that there is an increasing cost of effort, C, i.e.

$$
\mathrm{C}_{\mathrm{H}}>\mathrm{C}_{\mathrm{M}}>\mathrm{C}_{\mathrm{L}}
$$

where $\mathrm{H}, \mathrm{M}$, and $\mathrm{L}$ again indicate the effort choice. This holds in both periods. If (and only if) low effort is detected, the worker is either sacked (after stage 1) or loses his pension (after stage 2). For the sake of simplicity, the detection probability is exogenously determined to be $p$. We assume that the firm can make a full commitment not to renege and dismiss a worker who has supplied medium or high effort. ${ }^{5}$

This game can be solved through backward induction. The equilibrium is as follows. First, note that in a one-shot game it is off the equilibrium path for the worker to ever supply high effort because the cost to the worker is increasing in effort level and he can not be dismissed for supplying medium effort. The subgame perfect equilibrium solution is found by observing that if:

$$
\left(Z_{M}-C_{M}\right)>\left(Z_{L}-C_{L}\right)
$$

the joint surplus is maximized if the worker supplies medium effort in both periods. Thus the firm will be willing to compensate the worker for the cost of extra effort. Analyzing the worker's second period choice of whether to supply medium effort, we find he does so whenever:

$$
(1-\mathrm{p}) \mathrm{W}_{3}-\mathrm{C}_{\mathrm{L}} \leq \mathrm{W}_{3}-\mathrm{C}_{\mathrm{M}}
$$

\footnotetext{
${ }^{5}$ In a related paper we are examining the importance of this assumption to the wage offers made by firm players and the effort response of worker players. We conduct two additional treatments; first whereby the firm players cannot commit to wage offers and are allowed to change their wage offer at the start of each stage, and second whereby the firm player is allowed to change their wage offer at the start of each stage, but the worker player has a complete history of offers made by the firm player in previous rounds.
} 
His first period choice depends on what he expects to do in the second period. If condition (1) is fulfilled, i.e. that the pension is sufficiently high to deter low effort in the second period, then medium effort in stage 1 pays only if:

$$
(1-\mathrm{p})\left(\mathrm{W}_{2}+\mathrm{W}_{3}-\mathrm{C}_{\mathrm{M}}\right)-\mathrm{C}_{\mathrm{L}} \leq \mathrm{W}_{2}+\mathrm{W}_{3}-2 \mathrm{C}_{\mathrm{M}}
$$

Profit maximization implies that $\mathrm{W}_{2}$ and $\mathrm{W}_{3}$ are chosen such that (1) and (2) hold with equality. Notice that there is no restriction on $\mathrm{W}_{1}$, which does not influence the worker's behavior and can be viewed as a windfall or gift, and thus is zero in equilibrium. From (1) we obtain the equilibrium pension:

$$
\mathrm{W}_{3}=\left(\mathrm{C}_{\mathrm{M}}-\mathrm{C}_{\mathrm{L}}\right) / \mathrm{p}
$$

Substituting this in (2) we obtain:

$$
\mathrm{W}_{2}=\mathrm{C}_{\mathrm{M}}
$$

Thus, the equilibrium prediction is that firms will offer the wage profile ${ }^{6}\left(0, C_{M},\left(C_{M}-\right.\right.$ $\left.\mathrm{C}_{\mathrm{L}}\right) / \mathrm{p}$ ); workers will supply effort levels (MEDIUM, MEDIUM); and net productivity will be $\left(Z_{M}-C_{M}, Z_{M}-C_{M}, 0\right)$. The resulting payoffs over the three periods are $\left(-C_{M}, 0\right.$, $\left.\left(C_{M}-C_{L}\right) / p\right)$ for the worker and $\left(Z_{M}, Z_{M}-C_{M},-\left(C_{M}-C_{L}\right) / p\right)$ for the firm.

\section{Experimental Design}

We ran two treatments in this experiment to distinguish between optimal responses to incentives, gift exchange, and genuine mistakes. In the first treatment (henceforth referred to as the Human Treatment) ten subjects ( 5 workers and 5 firms) participated in each session. Subjects were assigned the role of firm or worker at the beginning of the experiment and kept their role throughout the session. Each session consisted of 20 rounds, with random matching of workers and firms in order to approximate a one-shot game in each round. We ran 6 sessions, thus there are observations for 30 worker players and 30 firm players over 20 rounds. The subjects were students at Royal Holloway and UCL, University of London.

The parameters of the model were set as follows: $p=.5, C_{L}=0, C_{M}=20, C_{H}=40$. Thus the worker players' optimal strategies are:

$$
\begin{aligned}
& \text { Stage 1: Effort }=\text { MEDIUM if } \mathrm{W}_{2} \geq 40 \text { or }\left(\mathrm{W}_{2}+\mathrm{W}_{3}\right) \geq 60 \text {; } \\
& \text { Effort }=\text { LOW otherwise }
\end{aligned}
$$

\footnotetext{
${ }^{6}$ Note that in the model the worker has a zero discount rate and thus their effort in stage 1 will respond the same way to payments in stage 2 or stage 3 . Thus the equilibrium can be characterized as $(0, \mathrm{X}, \mathrm{Y})$ where $0 \leq \mathrm{X} \leq \mathrm{C}_{\mathrm{M}}$ and $\left(\mathrm{C}_{\mathrm{M}}-\mathrm{C}_{\mathrm{L}}\right) / \mathrm{p} \leq \mathrm{Y} \leq \mathrm{C}_{\mathrm{M}}+\left(\mathrm{C}_{\mathrm{M}}-\mathrm{C}_{\mathrm{L}}\right) / \mathrm{p}$. In the presence of some small discount rate, the equilibrium described above is unique.
} 


\section{Effort $=$ LOW otherwise}

In the context of this experiment, we define gift giving by the firm player to be pay above the optimal levels (i.e. $\mathrm{W}_{1}>0, \mathrm{~W}_{2}>20$, or $\mathrm{W}_{2}+\mathrm{W}_{3}>60$ ) and gift giving by the worker player to be excess effort (i.e. high effort, given either low or medium was optimal or medium effort, given that low effort was optimal). We define gift exchange to be gift giving by both players in a given round. To test for gift exchange we examine first, whether excess effort occurs more frequently than insufficient effort, and, second, whether excess effort is more likely to occur following gift giving by the firm player. ${ }^{7}$

In order to distinguish between simple mistakes and gift giving, we ran a second treatment in which 30 worker players interacted with a computer firm player (henceforth referred to as the Computer Treatment). We assume that players would only wish to give gifts to other human players, thus excess or deficient effort levels in the Computer Treatment are viewed as genuine mistakes. Thus if there is a greater tendency for worker players to provide excess effort in the Human Treatment than in the Computer Treatment, we conclude that gift exchange influences the wage/effort relationship.

In order to make the comparison between the two treatments as straightforward as possible we took the values for $\mathrm{W}_{1}, \mathrm{~W}_{2}$, and $\mathrm{W}_{3}$ in the Computer Treatment from the actually chosen ones in the Human Treatment. In other words, the computer was programmed with 30 strategies based on the wage offers received over 20 rounds by each of the worker players in the Human Treatment. It is not possible for the Computer Treatment to precisely replicate the Human Treatment because the manner in which each round proceeds depends on the actions of the worker player and the coin toss. However, given the same actions by the worker players and the same coin toss outcomes, the payoffs will be the same in the two treatments.

A complete set of instructions given to subjects in the two treatments is presented in the Appendix to this paper.

\section{Results}

Let us first focus on the behavior of worker players. We examine the extent to which worker players supplied optimal effort, given the wage offers. We then examine the determinants of suboptimal effort levels to distinguish between genuine mistakes and gift giving.

The evidence shows that subjects typically supplied optimal effort, thus contract design has a strong influence on effort levels. In the human treatment, subjects supplied optimal effort levels 68.2 percent of the time. In the computer treatment, subjects

\footnotetext{
${ }^{7}$ A potential problem with the first part of this definition is that there exists an asymmetry between excess and deficient effort in the experiment design. It is possible for the worker player to provide excess effort regardless of the values of $\mathrm{W}_{1}, \mathrm{~W}_{2}, \mathrm{~W}_{3}$ by playing $\mathrm{HIGH}$; however, deficient effort is only possible if the optimal effort level is MEDIUM.
} 
supplied optimal effort levels 72.9 percent of the time. Subjects acted optimally the majority of the time regardless of whether the optimal action was low or medium. In the cases where the optimal was medium, worker players played medium 61.1 percent of the time and played high a further 12.0 percent of the time. In the computer treatment, the analogous figures are 79.2 percent and 6.5 percent. This evidence provides strong support for the prediction of the Lazear model that deferred compensation can be used to elicit increased effort.

A breakdown of the optimality of effort supplied is shown in Figure 2. There is considerable similarity between the two treatments. The proportion providing optimal effort increases over the course of the experiment. Another similarity is that in both treatments, a higher proportion of players supplied excess effort than deficient effort, particularly during the second stage. There are two differences between the computer and human treatments that deserve further attention. First, worker players supplied high effort more frequently in the human treatment (7.2 percent of observations) than in the computer treatment (5.7 percent of observations). Second, fewer workers supplied less than optimal effort (10.7 percent of observations) than in the computer treatment (6.4 percent). However, at the aggregate level, there is, at best, limited evidence that the two treatments are significantly different. Using data pooled across rounds and a Pearson $\chi^{2}$ test of the similarity of the distribution of insufficient, correct, and excess effort levels across the two treatments we reject at a 5 percent level $\left(\chi^{2}=12.75\right)$, the null hypothesis that the distributions are the same for stage 1 and accept at a null hypothesis that the distributions are the same for stage $2\left(\chi^{2}=2.57\right)$. However, this test assumes independence of observations, that is to say no interdependency of subjects' behavior across rounds. When the Pearson $\chi^{2}$ test is done on a round-by-round basis, we can not reject the similarity of the two distributions at a 5 percent level in any round of stage 1 and only reject it at a 10 percent level in 3 rounds. We do not reject the null hypothesis at even a 10 percent level for any round in stage 2 .

To determine whether suboptimal actions were mistakes or a form of gift giving, we have run a series of regressions analyzing the actions of the worker players. We use two sets of dependent variables in the analysis: first, ACTION ${ }_{1}$ and ACTION $_{2}(0=$ low, 1 $=$ medium, 2 = high), and, second, TOO LOW, TOO LOW, TOO HIGH , and TOO $\mathrm{HIGH}_{2}(1=$ action is suboptimally low or high in the first or second stage low, and 0 otherwise).

The first set of tests examines the determinants of ACTION And ACTION $_{2}$ using multinomial logit regressions. ${ }^{8}$ To provide sensitivity analysis for our results, we report three specifications for both treatments. The first specification is the most parsimonious, using only the wage offers $\left(\mathrm{W}_{1}, \mathrm{~W}_{2}\right.$, and $\left.\mathrm{W}_{3}\right)$ as explanatory variables. The Lazear model predicts that $\mathrm{W}_{1}$ will have no effect on effort and that $\mathrm{W}_{2}$ and $\mathrm{W}_{3}$ will have an equal positive effect on the probability that first period effort levels are medium. The model

\footnotetext{
${ }^{8}$ Because each subject plays 20 rounds there is a repeated measurement problem, with the consequence that standard methods will underestimate the variance of the coefficient. To accommodate repeated measurement, we ran the multinomial logit regressions clustering on individual subjects. See White (1980) and StataCorp (2003) for details.
} 
also predicts that only $\mathrm{W}_{3}$ will have a positive effect on the probability that second period effort levels are medium. The gift exchange model predicts that $\mathrm{W}_{1}, \mathrm{~W}_{2}$, and $\mathrm{W}_{3}$ will all have a positive effect on the probability that effort is high in both periods. The second specification adds two variables that capture the effect of subjects' understanding of the experiment: ROUND - the number of times that the subject has played the game, a measure of learning by doing; and TEST SCORE - the score that the subject attained on a pre-experimental quiz. ${ }^{9}$ If players intended to maximize their earnings (i.e. behave in accordance with the Lazear model), but made mistakes in their calculations, one would expect that more knowledgeable players would be less likely to play high, thus the coefficients on both ROUND and TEST SCORE would be negative in the regression for ACTION $=$ high. As medium effort may be either an optimal or suboptimal action, depending on the wage offer, we do not have any prior expectations for the sign of these coefficients in the regression for ACTION $=$ medium. The third specification adds subjects' personal characteristics from their answers to the post-experimental questionnaire. These variables include SEX, AGE, STUDY YEAR (undergraduate $=1,2$, 3 ; masters $=4 ; \mathrm{PhD}=5,6,7$ ), ECONOMICS (1 if majoring in economics), and session dummies. These variables are included as controls, and we do not have strong prior expectations on the signs of the coefficients. ${ }^{10}$

The regression results for the first and second rounds are shown in Tables 1 and 2, respectively. Overall the regressions have considerable explanatory power, with each specification being significant at even a .01 percent level. The regressions generally confirm the predictions of the Lazear model. In all specifications of the model $\mathrm{W}_{2}$ and $\mathrm{W}_{3}$ have a positive, statistically significant influence on the probability that subjects play medium effort in the first period; $W_{3}$ has a positive, statistically significant influence on the probability that subjects play medium in the second period. None of the wage offers for current or previous periods $\left(\mathrm{W}_{1}\right.$ in the regressions for stage 1 and $\mathrm{W}_{1}$ and $\mathrm{W}_{2}$ in the regressions for stage 2) has an impact on the probability that a subject supplies medium effort. The coefficients on the knowledge variables are also generally in accordance with the view that subjects intended to maximize earnings, but were computationally limited. In most specifications TEST SCORE has a significantly negative effect on the probability that the subject supplied high effort. In several specifications ROUND has a significantly negative effect on the probability that a subject supplied high effort. ${ }^{11}$

The results also provide some evidence for the gift exchange hypothesis. $\mathrm{W}_{2}$ and $\mathrm{W}_{3}$ have a positive, statistically significant influence on the probability that subjects supply high effort in the first period; and $\mathrm{W}_{3}$ has a positive, statistically significant

\footnotetext{
${ }^{9}$ Subjects took a quiz with 13 questions based on the instructions shown in the Appendix prior to the experiment commencing. Their computer screen indicated incorrect answers and subjects were required to resubmit answers to these questions. The experiment did not begin until each subject had correctly answered each of the questions. The variable TEST SCORE reflects the number of correct answers on the first time the subject submitted the quiz.

${ }^{10}$ The coefficients do not help to distinguish between gift giving and optimization based on incentives, and are thus not reported in the tables. A complete set of results is available on request from the authors.

${ }^{11}$ Anecdotally, this coincides with evidence from the post-experimental questionnaires. A few subjects indicated that they did not completely understand the game initially and improved their performance through trial and error.
} 
influence on the probability that subjects supply high effort in the second period. However, the coefficients on these variables are very similar in the Human and Computer Treatments, and thus we do not interpret them as gift exchange. One result that is consistent with gift exchange is the coefficient on $\mathrm{W}_{1}$ in the first period. In all specifications of the Human Treatment $\mathrm{W}_{1}$ has a positive, statistically significant influence on the probability that subjects played high effort, but in the Computer Treatment the coefficient on $\mathrm{W}_{1}$ is statistically insignificant. Though this is consistent with gift exchange, this effect is of considerably smaller magnitude than the effect of the incentive variables.

Table 3 shows the estimated probabilities that the worker player plays low, medium, or high given several hypothetical values of $\mathrm{W}_{1}, \mathrm{~W}_{2}, \mathrm{~W}_{3}$ based on the parsimonious specifications in Tables 1 and 2. Table 3 provides further support of the Lazear model. The estimated probability of making the optimal decision is over 50 percent for most values of $\mathrm{W}_{1}, \mathrm{~W}_{2}$, and $\mathrm{W}_{3}$; though there is a slight bias to playing low. Worker players did not respond to increases in $\mathrm{W}_{1}$; the estimated effort supplied in response to $(20,0,0)$ is virtually identically to that supplied in response to $(0,0,0)$ and similarly with $(20,20,40)$ and $(0,20,40)$. There is also some evidence of gift exchange. It is evident that worker players typically supplied more effort, and particularly were more likely to supply high effort, given the same wage offers in Human Treatment than in the Computer Treatment.

As a second set of tests we have run a series of logit regressions on the determinants of suboptimal effort. The dependent variables are TOO LOW (effort $=$ low, optimal effort $=$ medium) and TOO HIGH (effort $=$ high or effort $=$ medium, optimal effort = low). We ran two specifications of the regressions: first with just $\mathrm{W}_{1}, \mathrm{~W}_{2}$, and $\mathrm{W}_{3}$ as independent variables and second with the addition of TEST SCORE, ROUND, and personal characteristics. ${ }^{12}$ We interpret positive coefficients on $\mathrm{W}_{1}, \mathrm{~W}_{2}$, and $\mathrm{W}_{3}$ in the regressions on TOO HIGH as evidence of gift exchange.

The regression results for stage 1 and stage 2 are presented in tables 4 and 5 . There is some evidence of gift exchange in table 4. The coefficient on TOO HIGH is significantly positive in the Human Treatment, but insignificant in the Computer Treatment. A couple of other results merit further discussion. The coefficients on $\mathrm{W}_{2}$ and $\mathrm{W}_{3}$ are significantly negative in all specifications of in the first stage regression on TOO LOW for both the Human and Computer Treatments. One possible interpretation of this result is that subjects intended to act in accordance with the Lazear model, but are boundedly rational and capable of mistakes. When particularly high wage offers came through, they may have thought more carefully about their actions and thus been more likely to avoid supplying low effort and risking an end to the round. There is further evidence of intended earnings maximization coupled with evidence of bounded rationality from the knowledge variables. In six of the eight specifications there is a significantly negative coefficient on TEST SCORE, ROUND, or both, indicating that

\footnotetext{
${ }^{12} \mathrm{We}$ also ran the regressions with ROUND and TEST SCORE but without personal characteristics. The results were very similar to those of the regressions with personal characteristics and are thus not reported in this paper.
} 
subjects with a better understanding of the game were less likely to provide suboptimal effort levels.

We summarize our findings for worker players in the following:

Result 1 Worker behavior is predicted extremely well by the Lazear model. Subjects respond extremely well to the monetary incentives provided. There is, however, also some evidence for gift giving. When playing against human firm players, workers are more generous when being treated generously. Finally, we find evidence for bounded rationality and learning. Workers play more often optimally when they had an immediate understanding of the rules of the game and when they had gathered more experience by actually playing the game.

The behavior of firm players is more complex. Unlike the worker players whose decisions map directly into payoffs, the firm players must anticipate the worker players' response to their wage offer. To the extent that worker players' actual strategies deviate from equilibrium and these deviations change over time, firm players must also update their offers.

The expected payoff to the firm player can be calculated under the assumptions that 1) worker players always provide the equilibrium response to their wage offer and 2) worker players respond probabilistically in the manner estimated in Tables 1 and 2, parsimonious specifications. Under equilibrium response, the firm player's expected payoff is:

$$
\begin{aligned}
& 200-W_{1}-W_{2}-W_{3} \text { if }\left(W_{2}+W_{3}\right) \geq 60 \text { and } W_{3} \geq 40 \\
& 150-W_{1}-W_{2}-\mathrm{WW}_{3} \text { if } W_{2} \geq 40 \text { and } W_{3}<40 \\
& 100-W_{1}-p W_{2}-p^{2} W_{3} \text { otherwise }
\end{aligned}
$$

Under probabilistic response, the firm player's expected payoff is:

$$
\begin{aligned}
& .5 \mathrm{P}_{\mathrm{L} 1}+\mathrm{P}_{\mathrm{M} 1}+1.4 \mathrm{P}_{\mathrm{H} 1}+.5 \mathrm{P}_{\mathrm{L} 1}\left(.5 \mathrm{P}_{\mathrm{L} 2}+\mathrm{P}_{\mathrm{M} 2}+1.4 \mathrm{P}_{\mathrm{H} 2}\right)+.25 \mathrm{P}_{\mathrm{L} 1}+\left(\mathrm{P}_{\mathrm{M} 1}+\mathrm{P}_{\mathrm{H} 1}\right)\left(.5 \mathrm{P}_{\mathrm{L} 2}+\mathrm{P}_{\mathrm{M} 2}+\right. \\
& \left.1.4 \mathrm{P}_{\mathrm{H} 2}\right)-\left[\mathrm{W}_{1}+.5 \mathrm{P}_{\mathrm{L} 1} \mathrm{~W}_{2}+\left(\mathrm{P}_{\mathrm{M} 1}+\mathrm{P}_{\mathrm{H} 1}\right) \mathrm{W}_{2}+.25 \mathrm{P}_{\mathrm{L} 1} \mathrm{P}_{\mathrm{L} 2} \mathrm{~W}_{3}+.5 \mathrm{P}_{\mathrm{L} 1}\left(\mathrm{P}_{\mathrm{M} 2}+\mathrm{P}_{\mathrm{H} 2}\right) \mathrm{W}_{3}+\right. \\
& \left..5\left(\mathrm{P}_{\mathrm{M} 1}+\mathrm{P}_{\mathrm{H} 1}\right) \mathrm{P}_{\mathrm{L} 2} \mathrm{~W}_{3}+\left(\mathrm{P}_{\mathrm{M} 1}+\mathrm{P}_{\mathrm{H} 1}\right)\left(\mathrm{P}_{\mathrm{M} 2}+\mathrm{P}_{\mathrm{H} 2}\right) \mathrm{W}_{3}\right]
\end{aligned}
$$

where $\mathrm{P}_{\mathrm{JK}}$ is the probability that the worker player chooses effort $\mathrm{J}$ in stage $\mathrm{K}$, estimated using the regression coefficients from Tables 1 and 2, parsimonious specifications.

Using probability estimates from all rounds, we calculate the expected payoffs for all possible combinations of W1, W2, W3 in both treatments. Somewhat surprisingly, we find that the firm players' optimal strategy in the human treatment is $(0,0,0)$ giving an expected payoff of 112.62. The optimal strategy in the computer treatment is $(0,0,56)$ giving an expected payoff of 125.15. The optimal behavior in the computer treatment is to defer compensation and the implied optimal offer is close to one of the equilibria, $(0$, $0,60)$. 
Things change when we exclude the first third of the experiment and focus on more mature worker behavior. Taking the probability estimates from rounds 13-20, the optimal strategy in both treatments is to offer deferred compensation. The firm players' optimal strategy in the human treatment is $(0,24,49)$ approximately 25 percent over one of the equilibrium wage offers, $(0,20,40)$. In the computer treatment it is $(0,0,56)$, very close to one of the theoretical solutions, $(0,0,60)$. The expected payoffs are 109.70 in the human treatment and 129.38 in the computer treatment. In practice, offering the equilibrium wage offers of $(0,20,40)$ or $(0,0,60)$ is close to optimal. In each treatment, using either rounds 1-20 or rounds 13-20, both equilibrium strategies yield an expected payoff of at least 98 percent of the optimum. These figures provide further evidence that the Lazear model does an excellent job of predicting worker behavior. However, we also see once again that there is a small yet poignant effect of gift exchange. In the human treatment optimal wage offers are above the theoretical solution, but not so in the computer treatment.

Figure 2 shows the average offers made by firm players over 20 rounds. There are several observations that can be made from Figure 2. First, there is a sharp decline in the stage- 1 wage offer. In rounds 1-5 this averaged 34.3, in rounds 16-20 it averaged 12.8. As the optimal wage offer in period 1 is 0 under both the theoretical model and the probabilistic model, we take this to be evidence of a sharp learning effect for firm players. Second, after an initial decrease, there is an increase from about round 8 in the stage-3 wage offer. Over time the proportion of the wage offer that comes in stage 3 increases sharply: in rounds $1-5$ only 31.0 percent of the total offer is in stage 3 , in rounds 16-20 this figure is 42.3 percent. We argue that this provides evidence that the firm players are learning over time that deferred compensation will increase their expected payoff. This is strongly confirmed by Figure 3 which shows the expected payoff of the firm players over each round. There is a near monotonic increase in expected payoff.

We summarize our findings for firm players in the following:

Result 2 Firm behavior is predicted reasonably well by the Lazear model, though not as well as worker behavior. In addition, there is greater evidence of bounded rationality. In early rounds subjects offered excessively high wages and did not defer compensation. Over time subjects learned to reduce their wage offerings, particularly for the first stage, and to defer compensation. Consequently, firms increased their earnings over time.

\section{Conclusions}

There exists a sizeable theoretical literature showing that deferred compensation can be used by firms to elicit higher effort from their employees. The effect of deferred compensation on worker effort has thus far eluded empirical testing, as this sort of compensation structure is most likely to be used if it is impossible to measure all of the dimensions of short-term output and effort. This paper examines the relationship between the structure of compensation and worker effort using an experiment based on a simple three-period model. The experiment begins with a firm making a binding wage offer for 
the three periods. Then the worker player must decide whether to supply low, medium, or high effort in the first and second stage. In equilibrium, the firm offers a wage below marginal revenue product in the first period and above marginal revenue product in the third period and the worker supplies effort levels above what they would supply in a spot labor market in the first two periods.

We find that the worker players play according to the equilibrium about 70 percent of the time, thus it is possible for the firm player to induce higher effort using deferred compensation. We then examine the influence of gift exchange on the supply of effort by analyzing the determinants of suboptimal effort levels and by comparing the results of a treatment where the role of the firm is played by a human to a treatment where the role is played by a computer. We find some evidence of gift exchange. Worker players supplied somewhat more effort in the treatment with human firm players than in the treatment with a computer firm player. In particular, they were considerably more likely to supply high effort, which is always off the equilibrium path. Furthermore, in the human treatment worker players were more likely to supply both high effort and above equilibrium effort if they received the gift of a high wage in the first period.

Finally, we found that firm players who seem initially hesitant to defer compensation learn over time that it is beneficial to do so. Consequently, the share of wages that is paid in the last period increases almost monotonically as do firms' profits. 
Figure 1

A Deferred Compensation Contract

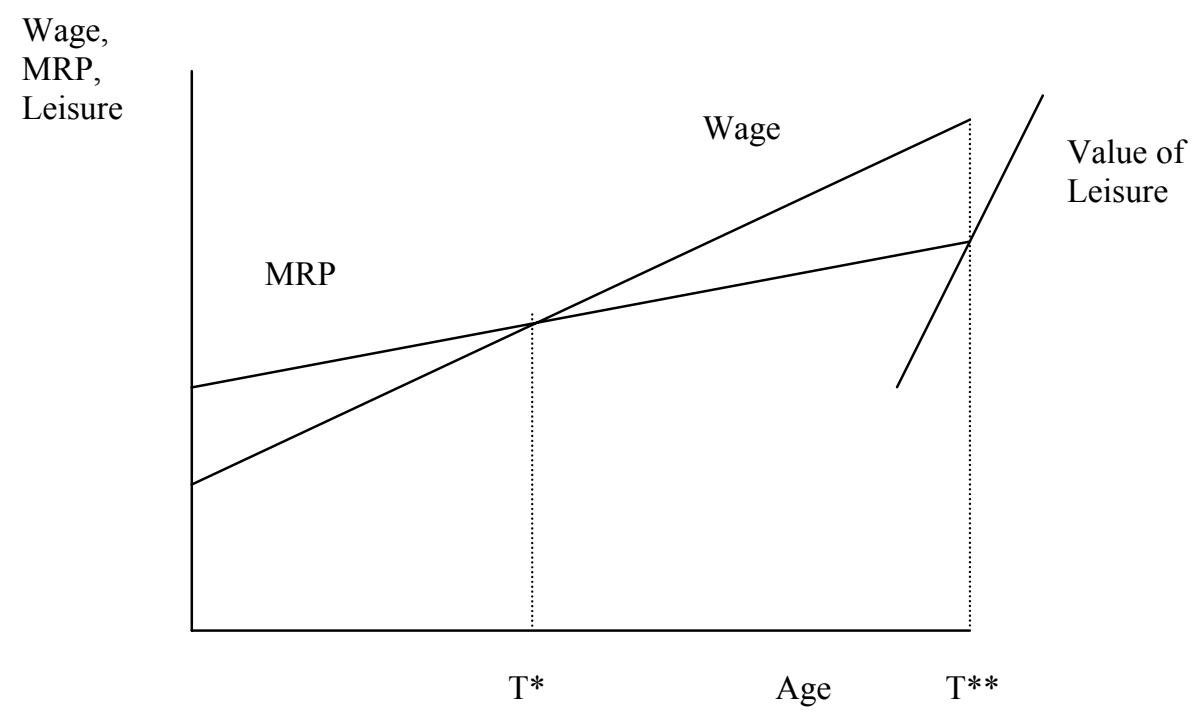



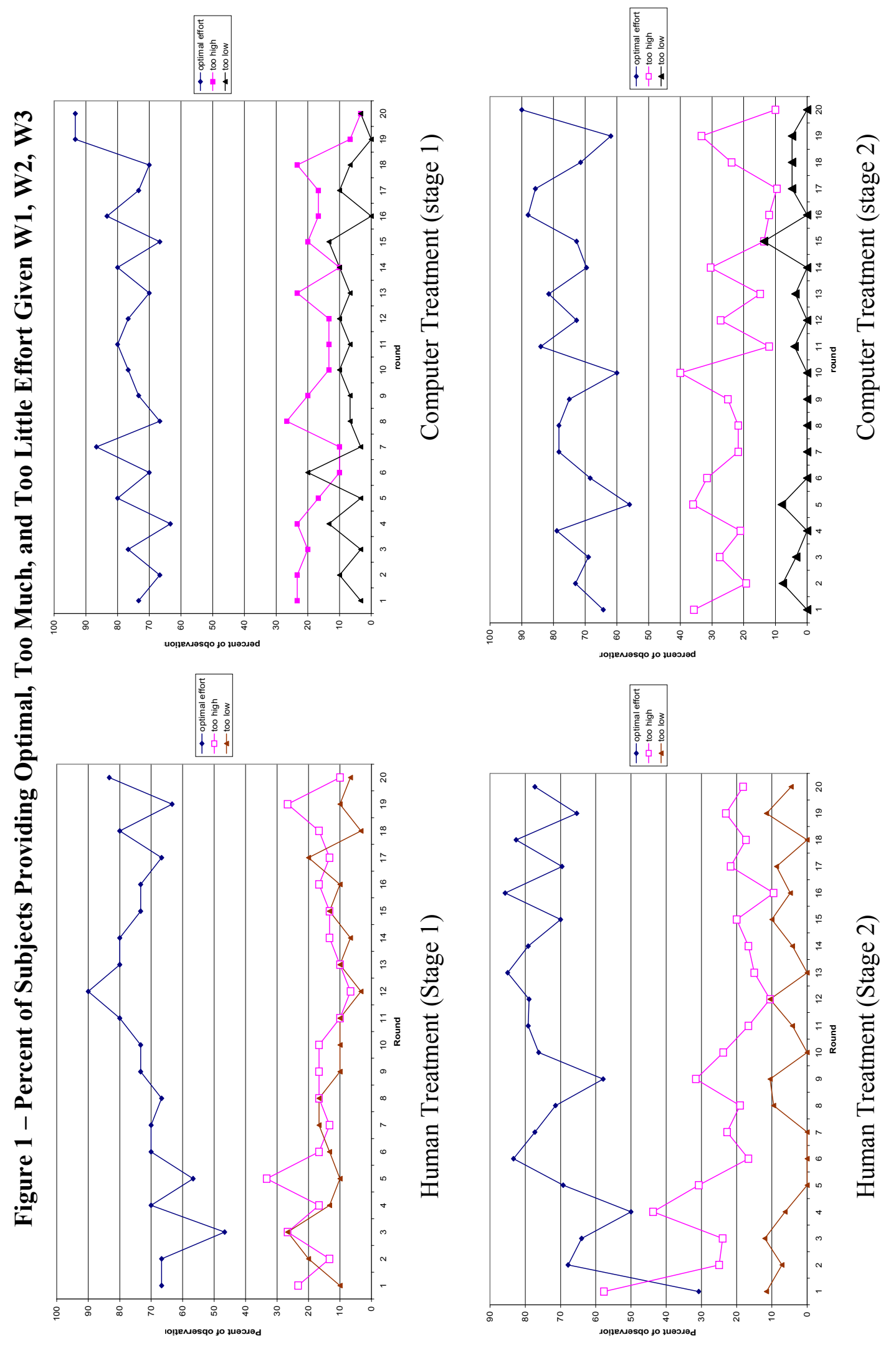

$n$

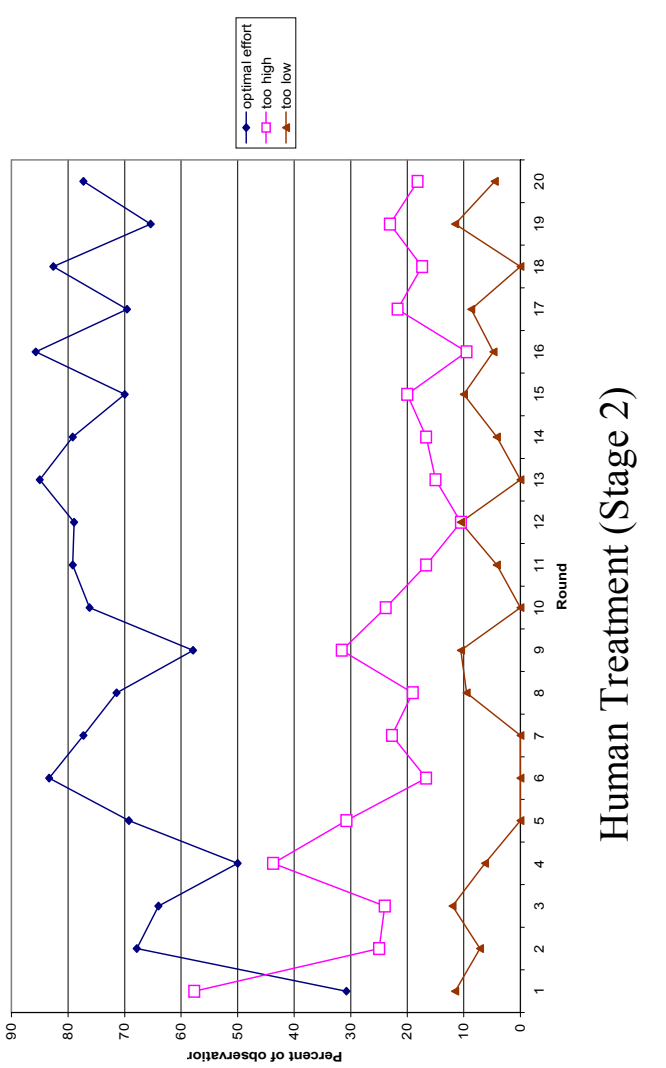


Figure 2

Average Wage Offers by Round

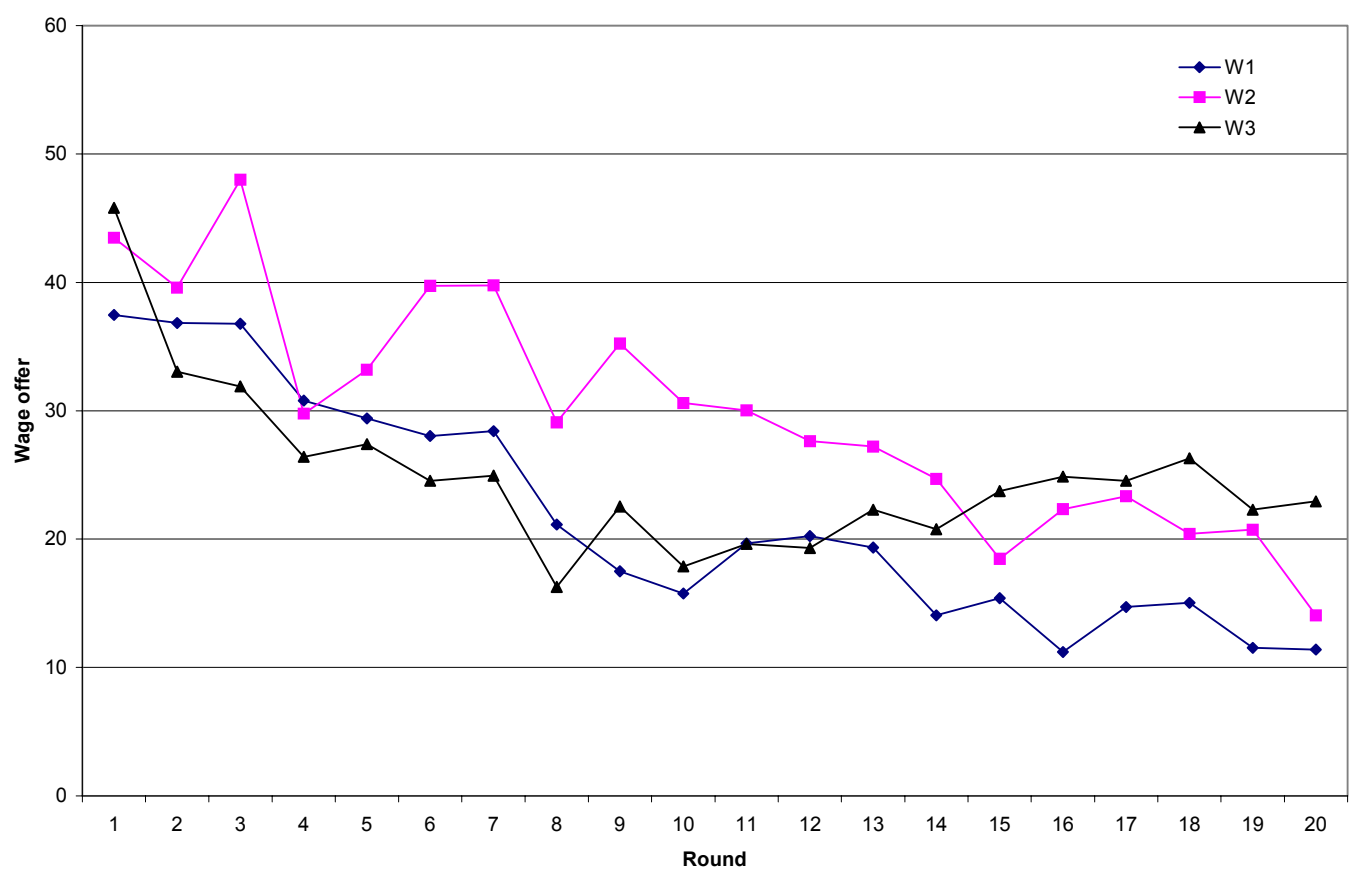


Figure 3

Average Expected Returns for Firm Players by Round

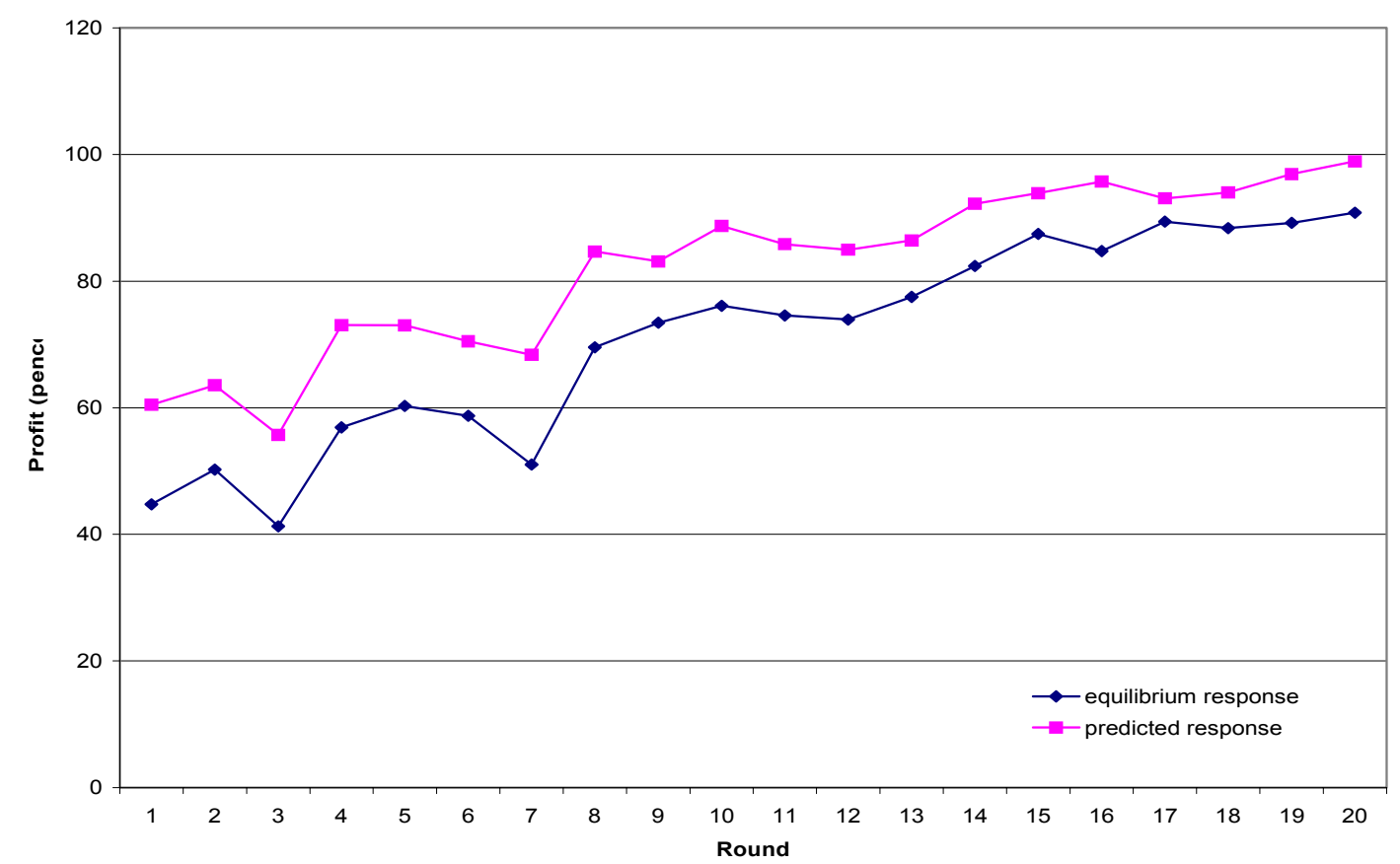

Note: Equilibrium response assumes that worker players always behave in accordance with the model described on pages 4-6. Predicted response assumes that workers behave probabilistically as estimated in tables 1 and 2. 


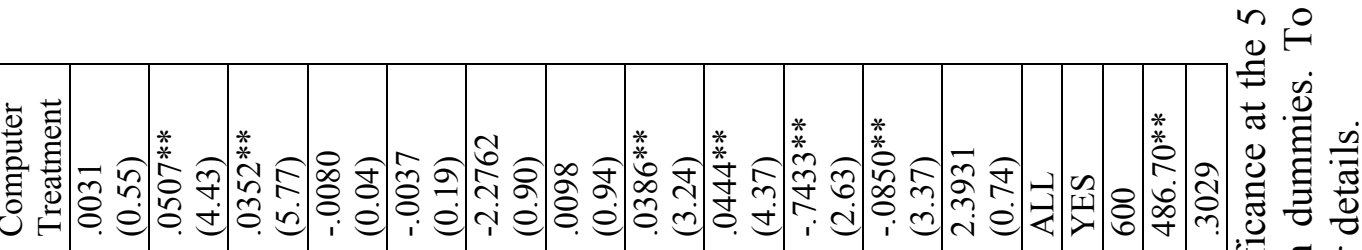

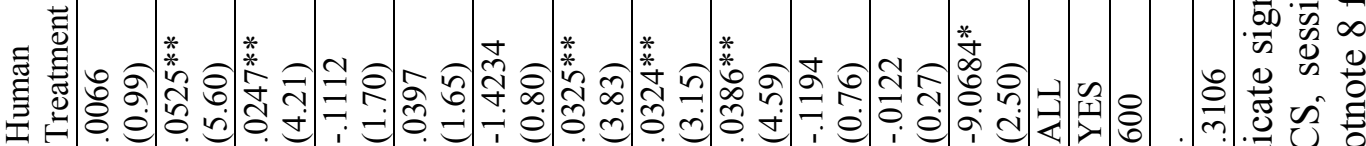

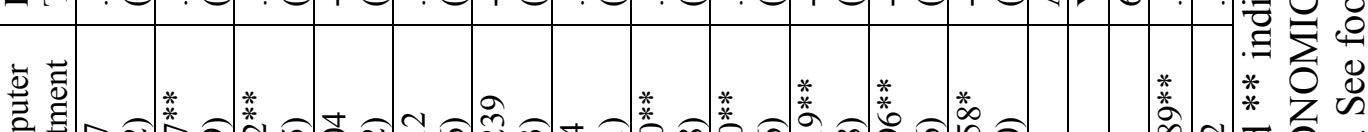

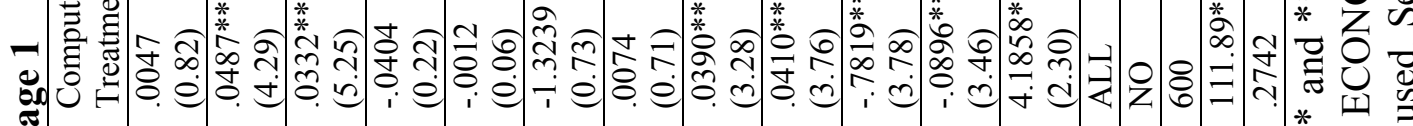

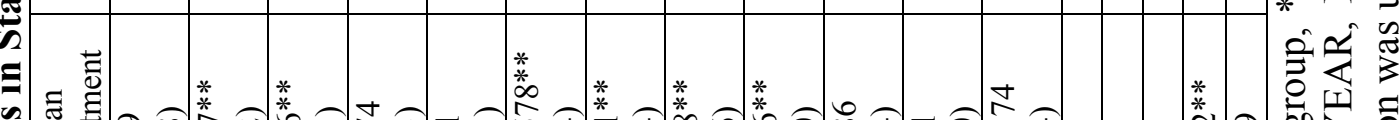

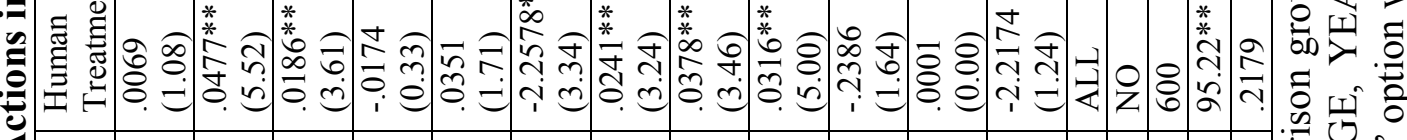

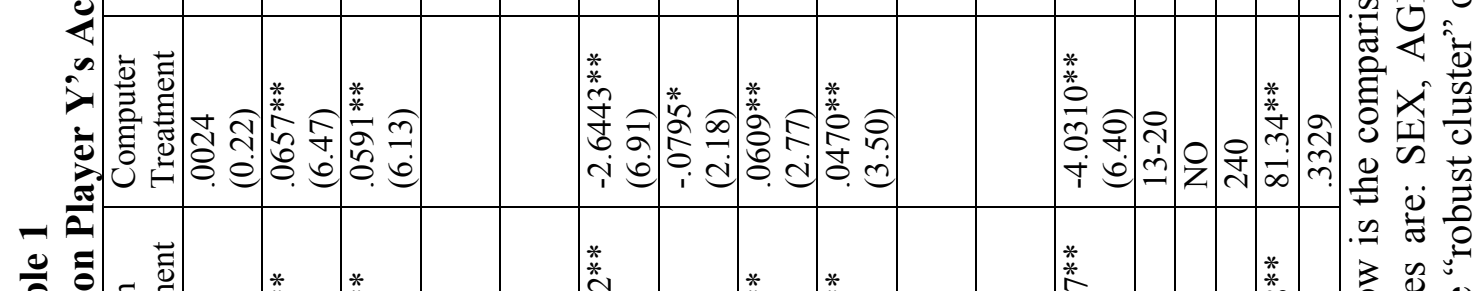

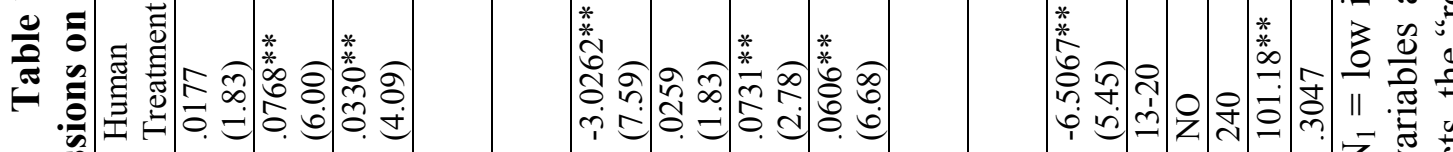

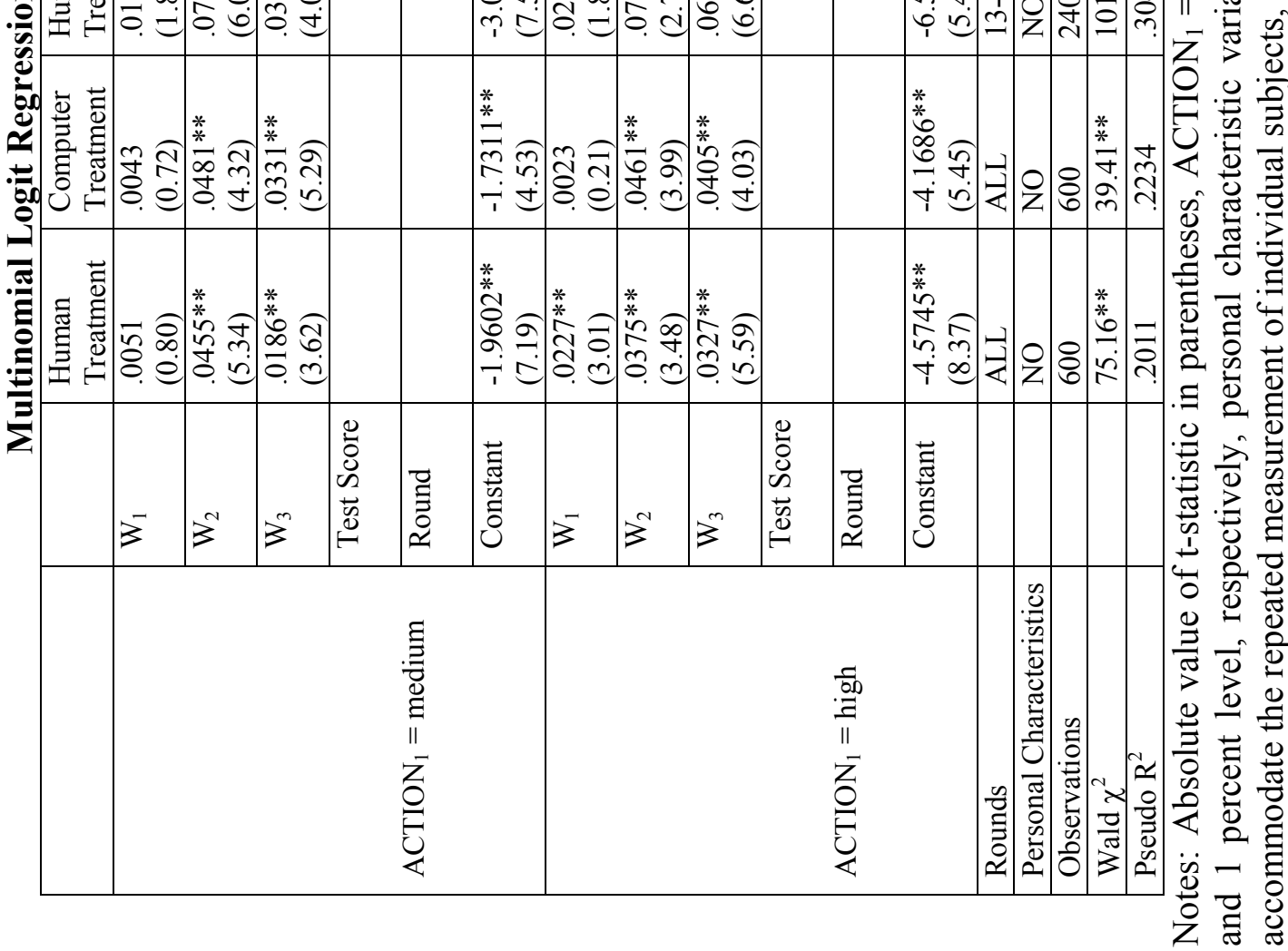




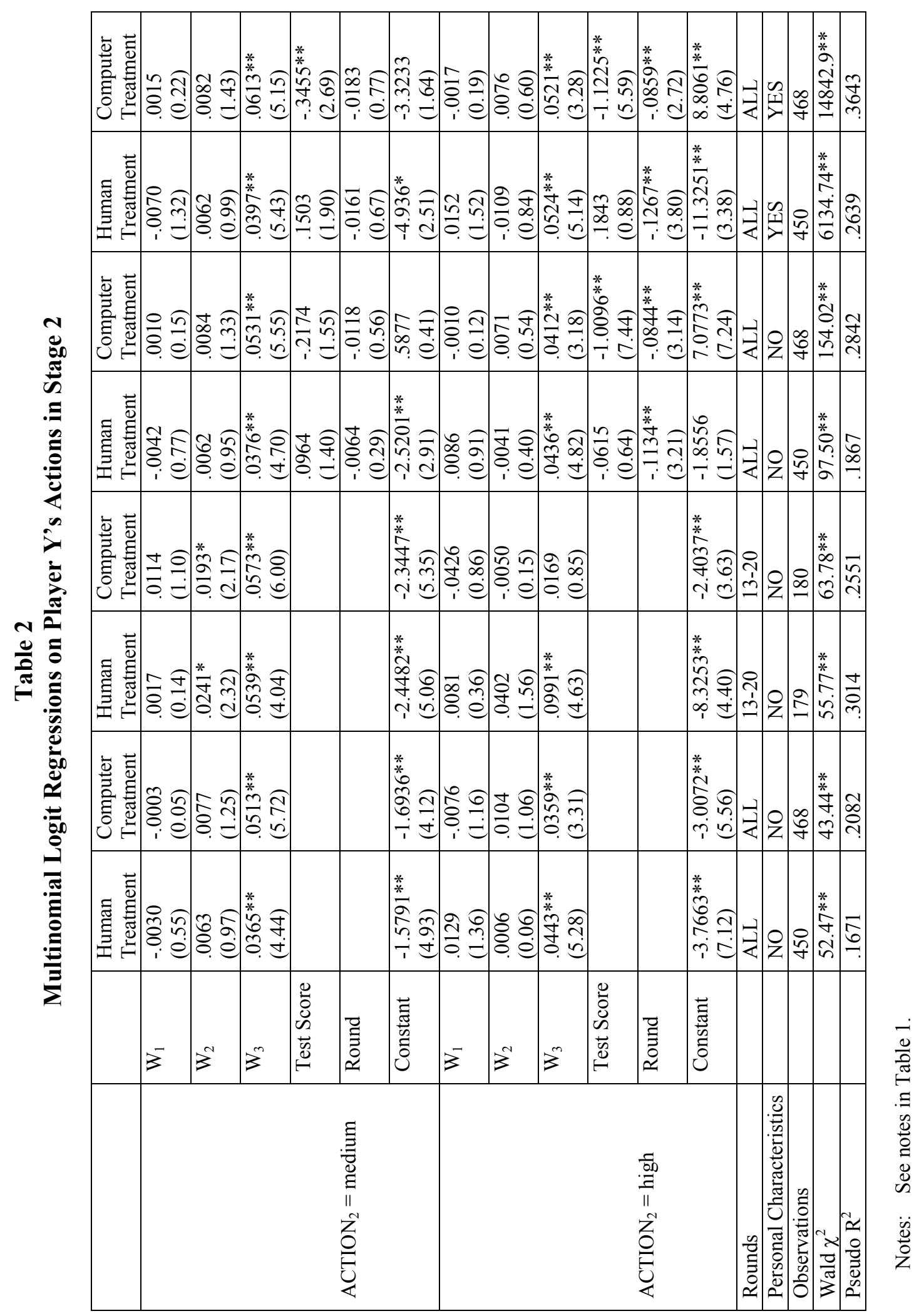



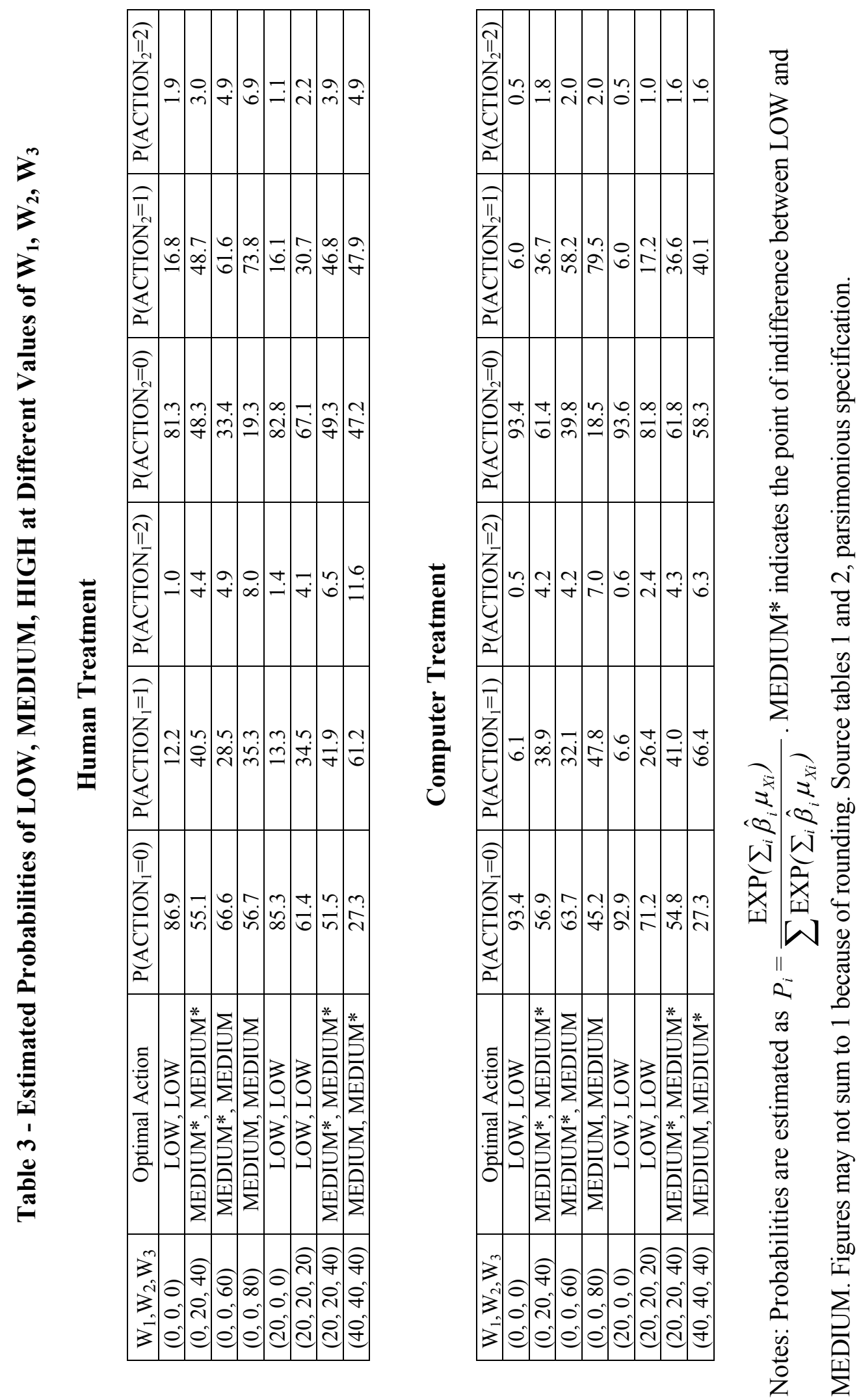


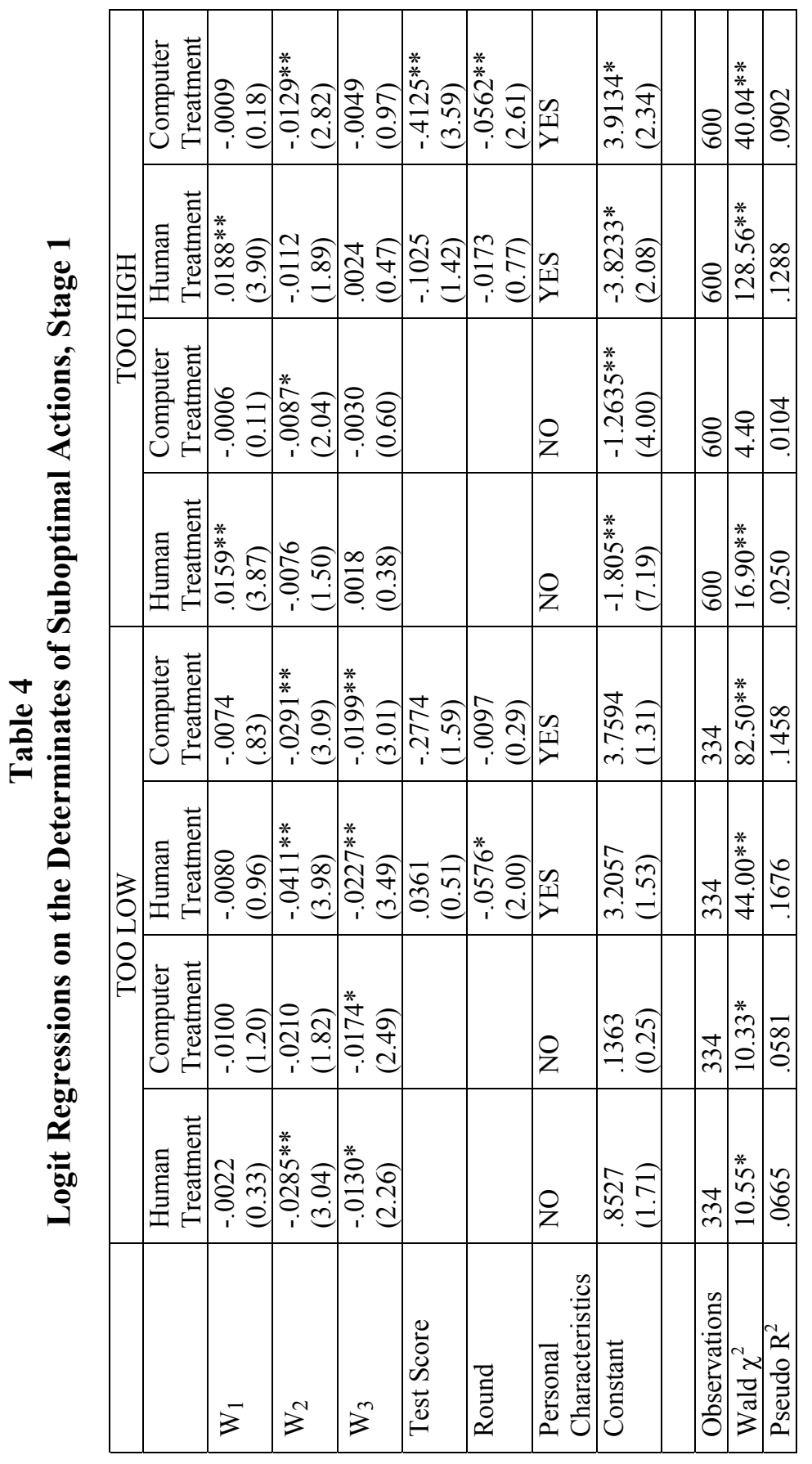

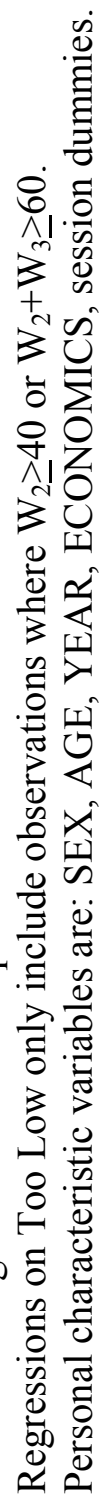

峁 


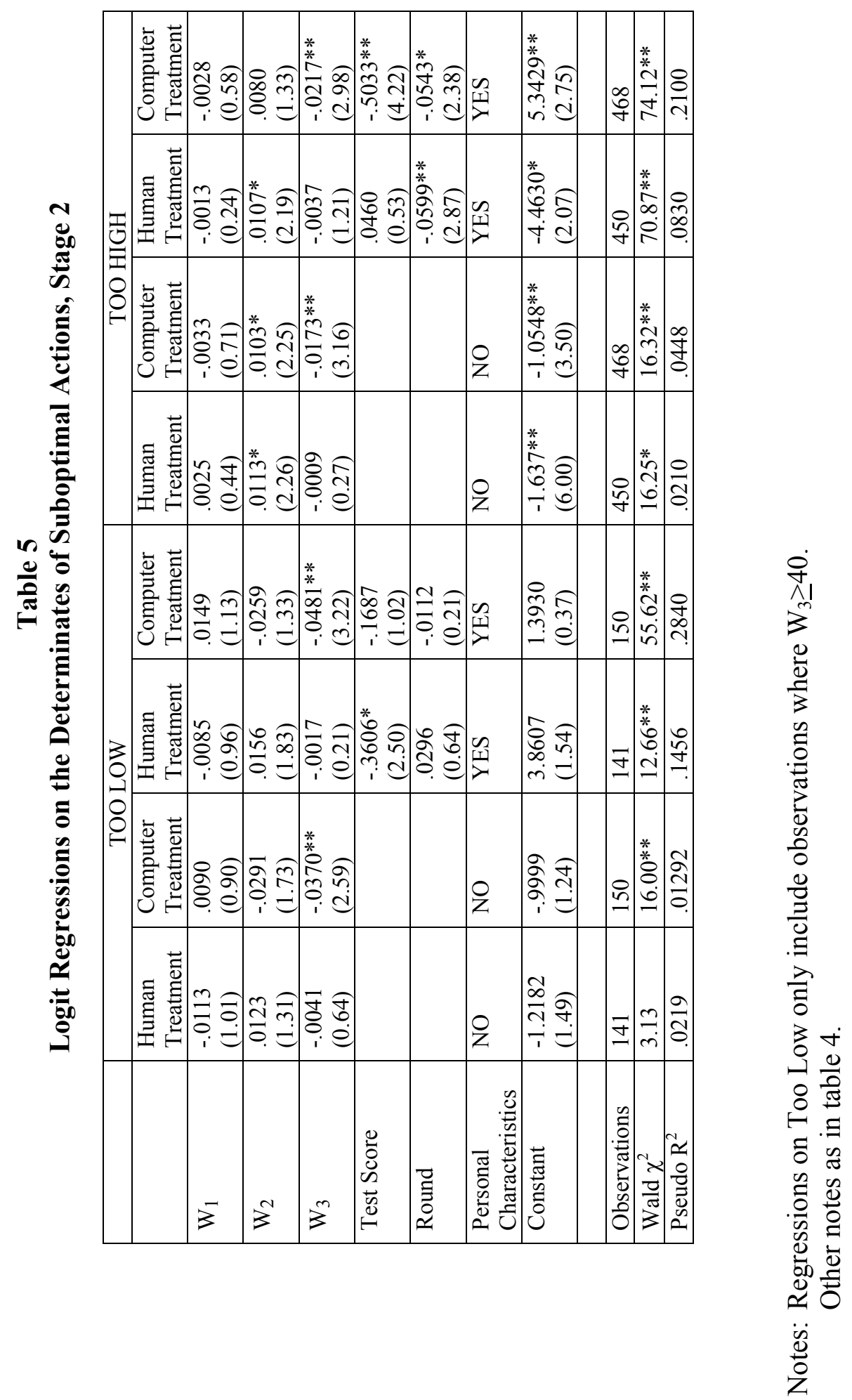




\section{References}

George Akerlof, 1982, "Labor Contracts as a Partial Gift Exchange", Quarterly Journal of Economics 97, $543-569$.

George Akerlof and Janet Yellen, 1990, "The Fair Wage-Effort Hypothesis and Unemployment", Quarterly Journal of Economics 105, 255-83.

Iris Bohnet, Bruno S. Frey, and Steffen Huck, 2001, "More Order With Less Law: On Contract Enforcement, Trust, and Crowding", American Political Science Review 95, 131 144.

Ernst Fehr and Armin Falk, 1999, "Wage Rigidity in a Competitive Incomplete Contract Market”, Journal of Political Economy 107, 106-134.

Ernst Fehr, Simon Gachter, and Georg Kirchsteiger, 1997, "Reciprocity as a Contract Enforcement Device: Experimental Evidence”, Econometrica 65, 833-860.

Ernst Fehr, Georg Kirchsteiger, and Arno Riedl, 1993, "Does Fairness Prevent Market Clearing?", Quarterly Journal of Economics 108, 437-460.

Ernst Fehr, Georg Kirchstieger, and Arno Ried1, 1996, "Involuntary Unemployment and Non-Compensating Wage Differentials in an Experimental Labour Market", Economic Journal 106, $106-121$.

Ernst Fehr, Alexander Klein, and Klaus M. Schmidt, 2001, "Fairness, Incentives, and Contractual Incompleteness", University of Zurich, Working Paper No. 72.

Jagadeesh Gokhale, Erica Groshen, and David Neumark. "Do Hostile Takeovers Reduce Extramarginal Salary Payments?" Review of Economics and Statistics, 77, 3 (August 1995): 470-85.

Robert Hutchens, "A Test of Lazear's Theory of Delayed Payment Contracts," Journal of Labor Economics (October, 1987), S153-S170.

Edward Lazear, 1979, "Why is there Mandatory Retirement?", Journal of Political Economy 87, 1261-64.

Edward Lazear, "Performance Pay and Productivity", American Economic Review, 90 (December 2000), 1346-1361.

Canice Prendergast, "The Provision of Incentives in Firms", Journal of Economic Literature 37, 1 (1999), 7-63. 
Steven Salop and Joanne Salop, "Self-Selection and Turnover in the Labor Market," Quarterly Journal of Economics, 90, 4 (1976), 619-27.

Andrew Seltzer and David Merrett, "Personnel Practices at the Union Bank of Australia: Panel Evidence from the 1887-1900 Entry Cohorts", Journal of Labor Economics 18 (2000), 573-613.

StataCorp. 2003. Stata Statistical Software: Release 8.0 User's Guide. College Station, TX: Stata Corporation, 271-275.

Halbert White, "A heteroscedasticity-consistent covariance matrix estimator and a direct test for heteroscedasticity”, Econometrica 48 (1980), 817-838 


\title{
Appendix: Instructions to Subjects
}

\section{Human Treatment}

\author{
Welcome to our experiment!
}

Please be quiet during the entire experiment. Do not talk to your neighbours and do not try to look at their screens. Simply concentrate on what you have to do. If you have any questions, please raise your hand. We will come to you and answer it privately.

You are participating in an economics experiment in which you interact with other participants for twenty rounds. Depending on your choices, the other participants' choices and luck you can earn a considerable amount of money. The amount of money you will receive depends on how well you understand these instructions, so read carefully. You will receive the money immediately after the experiment.

In each round you will interact with one other participant who is chosen at random. Once a round is over, you will be matched with a new participant, again at random.

At the beginning of the experiment each participant is assigned one of two roles, either X or Y. Everybody keeps their role during the entire experiment.

Let us now describe what happens in each of the 20 rounds. At the beginning of the round $\mathrm{X}$ has to offer $\mathrm{Y}$ some money. More specifically, he has to decide about three different amounts that will be paid to $\mathrm{Y}$ at stages $1,2,3$ of the round. Depending on the actions of $Y$, the round may end before stage 2 or 3 , in which case the amount offered by X will NOT be paid for those stages. After X has made the offer of some money, Y has to take up to two decisions that determine the total earnings of both $\mathrm{X}$ and $\mathrm{Y}$.

Sounds complicated? Don't worry. Here is a detailed description of the entire round.

At the start of each round X decides about three different amounts that he is willing to pay to Y. Let's call these amounts W1, W2, and W3. The value of each W1, W2, and W3 can be any amount between $£ 0.00$ and $£ 1.20$. This is the only decision that $\mathrm{X}$ will make during the round, but the cash payoff of that decision depends on the process described below, so everyone should read on carefully.

$\mathbf{1}^{\text {st }}$ stage: $\mathrm{Y}$ is informed about $\mathrm{W} 1, \mathrm{~W} 2$, and $\mathrm{W} 3$. Then he faces his own choice: He has to pick one of three different actions, which we call LOW, MEDIUM, and HIGH. Each of these three actions cause some costs for $\mathrm{Y}$ and some benefits for X. Let's call these amounts COST1 and BENEFIT1.

If $Y$ chooses LOW, he faces COST1 of $£ 0.00$, while X earns BENEFIT1 of $£ 0.50$. If $Y$ chooses MEDIUM, he faces COST1 of $£ 0.20$, while X earns BENEFIT1 of $£ 1.00$. If $Y$ chooses HIGH, he faces COST1 of $£ 0.40$, while X earns BENEFIT1 of $£ 1.40$.

If $\mathrm{Y}$ chooses MEDIUM or HIGH he receives $(£ 0.40+\mathrm{W} 1-\mathrm{COST} 1)$. The round then continues with stage 2. If $Y$ has chosen LOW, chance decides whether the round continues or not. More specifically, the computer will flip a coin. If it lands on heads, the round continues to stage 2 . If the coin lands on tails, the round is over. The final payoffs received by the two players for the round are as follows:

$\mathrm{X}$ receives $(£ 1.00-\mathrm{W} 1)$

$\mathrm{Y}$ receives $(£ 0.40+\mathrm{W} 1-\mathrm{COST} 1)$ 
Both participants are informed about what happened so far and their earnings for the round.

$2^{\text {nd }}$ stage: Stage 2 is the same as stage 1., i.e., again Y decides whether to choose LOW, MEDIUM, or HIGH. This has the same payoff consequences as in stage 1 (i.e. COST2 and BENEFIT2 are the same as COST1 and BENEFIT1).

If $\mathrm{Y}$ chooses MEDIUM or HIGH he receives (W2 - COST2) in addition to his earnings from stage 1. The round then continues with stage 3 . If $\mathrm{Y}$ has chosen LOW, the computer will flip a coin. If it lands on heads, the round continues to stage 3 .

If the coin lands on tails, the round is over. The final payoffs received by the two players for the round are as follows:

$\mathrm{X}$ receives (BENEFIT1 + BENEFIT2 $-\mathrm{W} 1-\mathrm{W} 2)$

$\mathrm{Y}$ receives $(£ 0.40+\mathrm{W} 1+\mathrm{W} 2-\mathrm{COST} 1-\mathrm{COST} 2)$

Both participants are informed about what happened so far and their earnings for the round.

$3^{\text {rd }}$ stage: There is no choice in stage 3 and what happens is very simple. X pays the amount W3 (which he has chosen in the very first stage) to Y. That is, if round 3 is reached, we will subtract W3 from X's total earnings in this round and will add W3 to Y's total earnings in this round.

The final payoffs received by the two players for the round are as follows:

$\mathrm{X}$ receives (BENEFIT1 + BENEFIT2 $-\mathrm{W} 1-\mathrm{W} 2-\mathrm{W} 3)$

$\mathrm{Y}$ receives $(£ 0.40+\mathrm{W} 1+\mathrm{W} 2+\mathrm{W} 3-\mathrm{COST} 1-\mathrm{COST} 2)$

At the end of the $3^{\text {rd }}$ stage both $X$ and $Y$ will be reminded of what happened in this round, i.e., they will see $\mathrm{X}$ 's choice of W1, W2, and W3 as well as Y's choices between LOW, MEDIUM, and HIGH. They will also see the final payoff for both $\mathrm{X}$ and $\mathrm{Y}$ in the round. Finally, you will see your total earnings so far, over all previous rounds.

At the end of the experiment you will be paid your total earnings over all 20 rounds in cash and be asked to sign a receipt.

This procedure may sound more complicated than it is. Take your time to read through the instructions again. And if you have any questions raise your hand. In a couple of minutes we will distribute an online questionnaire that we ask you to fill out. The purpose of this is simply to make sure that everybody fully understands the rules of the experiment before we actually start. You will need to answer each question correctly before beginning. 


\section{Computer Treatment}

\section{Welcome to our experiment!}

Please be quiet during the entire experiment. Do not talk to your neighbours and do not try to look at their screens. Simply concentrate on what you have to do. If you have any questions, please raise your hand. We will come to you and answer it privately.

You are participating in an economics experiment in which you interact with a computer for twenty rounds. Depending on your choices and luck you can earn a considerable amount of money. The amount of money you will receive depends on how well you understand these instructions, so read carefully. You will receive the money immediately after the experiment.

Let us now describe what happens in each of the 20 rounds. At the beginning of the round the computer offers you some money. The amount that the computer offers in each round has been pre-determined and cannot be influenced by your strategy. Depending on the your actions in stage 1 and 2 , the round may end before stage 2 or 3 , in which case the amount offered by the computer will NOT be paid for those stages. After the computer has made the offer of some money, you have to take up to two decisions that determine your total earnings.

Sounds complicated? Don't worry. Here is a detailed description of the entire round.

$\mathbf{1}^{\text {st }}$ stage: At the start of this stage the computer offers three different amounts that it will pay to you. Let's call these amounts W1, W2, and W3. The value of each W1, W2, and W3 can be any amount between $£ 0.00$ and $£ 1.20$.

You are informed about W1, W2, and W3. You then must make your own choice: specifically you must pick one of three different actions, which we call LOW, MEDIUM, and HIGH. Each of these three actions causes some costs for you. Let's call this amount COST1.

If you choose LOW, you face COST1 of $£ 0.00$.

If you choose MEDIUM, you face COST1 of $£ 0.20$.

If you choose $\mathrm{HIGH}$, you face COST1 of $£ 0.40$.

If you choose MEDIUM or HIGH you receive $(£ 0.40+\mathrm{W} 1-\mathrm{COST} 1)$. The round then continues with stage 2. If you chose LOW, chance decides whether the round continues or not. More specifically, the mastercomputer will flip a coin. If it lands on heads, the round continues to stage 2.

If the coin lands on tails, the round is over. The final payoff you receive for the round is:

$(£ 0.40+\mathrm{W} 1-\mathrm{COST} 1)$ where COST1 is zero because you chose LOW at stage 1

You are then informed about what happened so far and your earnings for the round. 
$\mathbf{2}^{\text {nd }}$ stage: In this stage you decide whether to choose LOW, MEDIUM, or HIGH. This has the same payoff consequences as in stage 1 (i.e. COST2 depends on your choice in the same way as COST1).

If you choose MEDIUM or HIGH you receive (W2 - COST2) in addition to your earnings from stage 1. The round then continues with stage 3 . If you chose LOW, the master-computer will flip a coin. If it lands on heads, the round continues to stage 3 .

If the coin lands on tails, the round is over. The final payoff you receive for the round is:

$(£ 0.40+\mathrm{W} 1+\mathrm{W} 2-\mathrm{COST} 1-\mathrm{COST} 2)$ where COST2 is zero because you chose LOW at stage 2

You are then informed about what happened so far and your earnings for the round.

$3^{\text {rd }}$ stage: You do not make any choices in stage 3 and what happens is very simple. The computer pays you the amount W3. That is, if stage 3 is reached, we will add W3 to your total earnings in this round.

The final payoff you receive for the round is:

$(£ 0.40+\mathrm{W} 1+\mathrm{W} 2+\mathrm{W} 3-\operatorname{COST} 1-\operatorname{COST} 2)$

At the end of the $3^{\text {rd }}$ stage you will be reminded of what happened in this round, i.e., see the values of W1, W2, and W3 as well as your choices between LOW, MEDIUM, and HIGH. You will also see the final payoff the round.

Finally, you will see your total earnings so far, over all previous rounds.

At the end of the experiment you will be paid your total earnings over all 20 rounds in cash and be asked to sign a receipt.

This procedure may sound more complicated than it is. Take your time to read through the instructions again. If you have any questions raise your hand. In a couple of minutes we will distribute an online questionnaire that we ask you to fill out. The purpose of this is simply to make sure that everybody fully understands the rules of the experiment before we actually start. You will need to answer each question correctly before beginning. We will also distribute another questionnaire at the end of the experiment. This will ask some basic information about yourself and the approach you took during the experiment. 